\title{
Numerical Studies on Thermo-Hydraulic Characteristics of Turbulent Flow in a Tube with a Regularly Spaced Dimple on Twisted Tape
}

\author{
Harish H. V. ${ }^{1}$, Birlie Fekadu ${ }^{2,}{ }^{*}$, Manjunath K. ${ }^{1}$ \\ Department of Mechanical Engineering, Government Engineering College, Hassan, India \\ School of Mechanical and Industrial Engineering, Institute of Technology, Debre Markos University, Ethiopia
}

\section{ARTICLE INFO}

Article history:

Received 15 June 2021

Received in revised form 28 July 2021

Accepted 29 July 2021

Available online 8 August 2021

\section{Keywords:}

Finite volume method; Turbulent flow; Friction factor; convection heat transfer; Dimple twisted tape

\section{ABSTRACT}

Heat transfer augmentation is an important concern due to the increase in heat management problems in thermal systems. There are many techniques for enhancement of heat transfer, by active and passive techniques. A commonly used passive technique to enhance heat transfer is by inserting twisted tapes in tubes. This work presents a numerical study on Nusselt number, friction factor, and thermal performance characteristics through a circular pipe built-in with/without dimples on twisted tape. The analysis results for a turbulent flow range of $4500 \leq R e \leq 20000$ are obtained with a twist ratio of the strip is 3.0. The analysis is carried for full-length tape with constant heat flux. The governing equations are numerically solved by a finite volume method using the RNG $\mathrm{k}-\varepsilon$ model. The simulation results of Nusselt number versus Reynolds number of the plain, plain twisted tape and dimple twisted tape tube with the experimental data give a variation of $4.15 \%, 3.89 \%$, and $7.65 \%$. The friction factor of the dimple twisted tape tube is 60 to $70 \%$ higher than that of the plain twisted tube at different Reynolds numbers. The thermal performance factor of the dimple twisted tape and plain twisted tape tube is 30 to $35 \%$ respectively higher than that of the plain tube. Due to thermal performance factor is above unity yields a promising heat transfer enhancement. By the present study, an optimum geometrical parameter can be selected for use in heat exchangers.

\section{Introduction}

A commonly used passive technique to enhance heat transfer is by inserting twisted tapes in tubes. By inserting twisted tape, a swirl flow will be produced thereby enhancing the heat transfer coefficient, however, an increase in friction factor is considered a disadvantage of the technique.

Experimental work of Seemawute and Eiamsa-ard [1] on twisted tape found that with less width of twisted tape insert in a round tube, the pressure drop will be less thereby giving more augmentation of energy transfer.

Liao and Xin [2] investigated experimentally and found that the Stanton number of the finned tube was increased up to 5.8 times the smooth tube with continuous twisted tape, while the friction factor was increased almost 6.5 times the empty smooth tube.

\footnotetext{
* Corresponding author.

E-mail address: birliefekadu83@gmail.com (Birlie Fekadu)
} 
Yadav and Padalkar [3] conducted a computational investigation of turbulent energy transfer enhancement characteristics of fluid flow inside a circular tube with a partially decaying and partially swirling flow. More energy transfer was provided by the flow in the induced tube than that in the plain tube.

Chiu and Jang [4] conducted numerical and experimental studies on thermo-hydraulic characteristics inside a circular tube with longitudinal strip inserts (both with hole and without holes) and twisted tape inserts at three different angles ("15.3", $24.4^{\circ}$ " and 34.3") and found "heat transfer coefficient and pressure drop in the tube with longitudinal strip inserts were higher than a plain tube. The coefficient of heat transfer and pressure drop were respectively 13-28 percent and 140-220 percent higher than those of the plain tubes.

Abed et al., [5] has numerically studied the characteristics of heat transfer and friction factor for various twisted tapes ( $\mathrm{V}$-cut) and (PTT) inserted within a horizontal tube, with twisted ratios (TR=4.0 \& 6.0). Abed et al., [5] the following conclusions are therefore drawn. The use of twisted tape enhances the intensification of energy transfer. A better heat transfer increase than that of the (PTT) with all twisted ratio values is given by the $\mathrm{V}$-cut twisted tape.

The physical behavior of thermal and fluid flow in a tube with loose-fit twisted tape in a turbulent flow regime has been published by Eiamsa-ard et al., [6]. The effect of the clearance of the twisted tapes energy transfer characteristics between the edge of the tape and the wall of the tube is investigated numerically by applying the various turbulent models at two different twist ratios of 2.5 and 5.0. The result of the simulation showed that the twist with the lowest clearance ratio provided the highest heat transfer intensification and the highest thermal efficiency index.

Promvonge and Eiamsa-ard [7] used combined inserts of conical ring and tape insert to intensify the heat transfer. Chang et al., [8] used a broken twisted tape inserts to analyze heat transfer characteristics of pressure drop and Nusselt number. The effect of TT in the smooth tube was studied in various configurations like conventional, and found an augmentation of energy transfer and pressure drop $[9,10]$. And also, they stated that the heat transfer coefficient and friction factor also increased.

Salman et al., [11] conducted numerical investigations using CFD simulation of heat transfer and friction factor characteristics in swirling flow conditions. The tube fitted with quadrant-cut twisted tape (QCT) were significantly increased with a decrease in twist ratio and cut depth. In addition, the QCT insert configuration with a twist ratio of 2.93 and a cut depth of $0.5 \mathrm{~cm}$ produces a higher rate of heat transfer than other twist ratios.

Eiamsa-ard et al., [12] studied influences of straight delta winglet(S-DWT) and oblique deltawinglet (O-DWT) twisted tape for various wing cut depth ratios. O-DWT was found more efficient than S-DWT, leading to an improvement in the rate of heat transfer.

For the turbulent flow range $4000<\mathrm{Re}<20,000$, Sarviya and Fuskele [13] experimentally investigated heat transfer and pressure drop effects in a circular tube inserted with continuous rectangular cut edges of the twisted tape with twist ratios 5 and 3. Compared to plain tubes, an increase in the heat transfer rate along with the friction factor is observed by reducing the twist ratio. The heat transfer rate is improved by twisted tape inserts with continuous rectangular cut edges for twist ratios 5 and 3 by 2.21 and 2.23 times that of plain tubes and 1.63 and 1.42 times that of conventional twisted tape. The effects of twisted tape in various configurations such as clockwise and counter-clock wise, regularly spaced dual, perforated, and even short length were studied and most of the studies showed energy transfer intensification and pressure drop with different inserts were recorded [14-17].

One of the key passive techniques which can increase the heat transfer rate is the twisted tape (TT) insert. There are numerous types and configurations of TTs which researchers have widely 
studied in fluid flows, including turbulent and laminar flows [18]. Using TTs in a channel usually contributes to a high rate of heat transfer and a decrease in pressure at the same time. The thickness of the thermal boundary layer that goes lower when the TT is used is the cause of the increased heat transfer. So, this small, viscous sub-layer makes the transfer of heat very important. The increased pressure drop is also due to blockage of flow, greater contact surface area with long flow direction, and even the swirl flow effect leads to higher turbulent intensity [18].

It can be inferred from the review work of Maradiya et al., [19] that the increase in heat transfer occurs in all cases due to a reduction in the region of the flow cross-section, an increase in turbulence, and tangential flow formed by different types of inserts. The heat transfer enhancement is significantly influenced by geometrical insert parameters such as width, length, twist ratio, etc. In the case of multiple twisted tapes, twist direction is also an important parameter, because the counterswirl flow performs better than the co-swirl. The function of inserts is more important in the laminar flow than in turbulent flow in increasing turbulence strength. Therefore, wire coil inserts are used to enhance heat transfer in a turbulent flow.

Experiments performed by Vashistha et al., [20] for single twisted tape, co-swirl, and counterswirl centered double twisted tape and four co-swirl and counter-swirl centered twisted tapes. The counter-swirl performed better than the co-swirl and the four twisted tape performed better than the double and single twisted tape, they concluded.

The effect of artificial roughness on heat transfer enhancement was studied by García et al., [21]. In a circular tube fitted with ball turbulators at a Reynolds number range of 5000-35000, the heat transfer and friction factor characteristics of turbulent water flow are investigated by Yuan et al., [22] through numerical simulation and the Nusselt number increases and the friction factor decreases as the number of Reynolds increases in a tube with BTs. For an improved tube, the Nusselt number is about 1.26-2.01 times as much as that of the plain tube, while the friction factor raises sharply by about 3.74 to 10.27 times.

To test the thermal-hydraulic efficiency of a turbulent single-phase flow inside a tube fitted with a square cut twisted tape (STT), a numerical solution was performed by Wijayanta et al., [23]. Also researched for contrast was the classically twisted tape (CTT) insert. As the K- the renormalized turbulent model was used for the Reynolds number range of 8000-18000 with water as the working fluid, different twist ratios of $2.5,4.5$, and 6.5 were investigated. The empirical results revealed that the tube fitted with the STT with the twist ratio of 2.5,4.5 and 6.5 resulted in an improvement of 45.4-80.7 percent and 2.0-3.3 times respectively in the values of Nusselt number and friction factor in the inner tube relative to the plain tube (PT). In comparison maximum, the thermal efficiency of 1.23 was achieved.

Juera-ong et al., [24] have been investigated the heat transfer and flow characteristics of a single row of orifice jets on boundary layer on a flat plate by dividing in to two parts and their results showed that increasing momentum flux ratio can enhance heat transfer significantly.

Japar et al., [25] numerically investigates the effects of hydrodynamic entrance on heat transfer and fluid flow for 100-800 Reynolds number at constant heat flux. And their result reveals that hydro dynamic and heat transfer increases as Reynolds number increases.

Yusof et al., [26] investigates numerical stagnation point flow and radiative heat transfer of a nonNewtonian fluids through slippery Riga plate with the effects of thermal radiation, magnetic field, velocity and thermal slip, and viscous dissipation. And they have been found that temperature decreases when the velocity slip parameter and thermal slip parameter are increased.

Harish et al., [27] have been numerically investigated flow field in order to augment heat transfer, through a circular pipe built in with and without Dimples on twisted strip. And their result showed 
that the Dimple twisted tape and plain twisted tape tube is 4 to $15 \%$ and 3 to $12 \%$ respectively higher than that of plain tube in terms of thermal performance factor.

However, the above-mentioned studies focused on thermo-hydraulic characteristics of plain tubes and twisted tubes only. And also, there appeared only a few studies were concerned with the comparisons of thermal performance factor and friction factor of PT, PTT, and DTT. This research aims to investigate the thermo-hydraulic characteristics of the turbulent flow for PT, PTT, and DTT were checked in the present work with the experimental results of Seemawute and Eiamsa-ard [1], Gnielinski correlation, and the Kidd correlation. By the present study, an optimum geometrical parameter can be selected for use in heat exchangers.

\section{Methodology}

\subsection{Description and Assumption of Model}

The geometry of the flow domain is as shown in Figure 1; pipe length is $1000 \mathrm{~mm}$ with an ID of $19 \mathrm{~mm}$ the thickness of the strip is $1 \mathrm{~mm}$. The single twisted ratio of the strip is 3.0 and the domain of full-length tape has been chosen. The numerical analysis will be validated with the experimental work of Seemawute and Eiamsa-ard [1] which is one of the sources.

\subsection{Model Geometry}

The various geometry was used for analysis shown in Figure 1 has the dimension of length $1000 \mathrm{~mm}$, internal diameter $19 \mathrm{~mm}$. The full-length twisted tape has been selected for analysis which has a thickness, pitch, and width of 1,54 , and $18 \mathrm{~mm}$. Further to intensify heat transfer dimples are provided on the strip which is as shown in Figure 2.

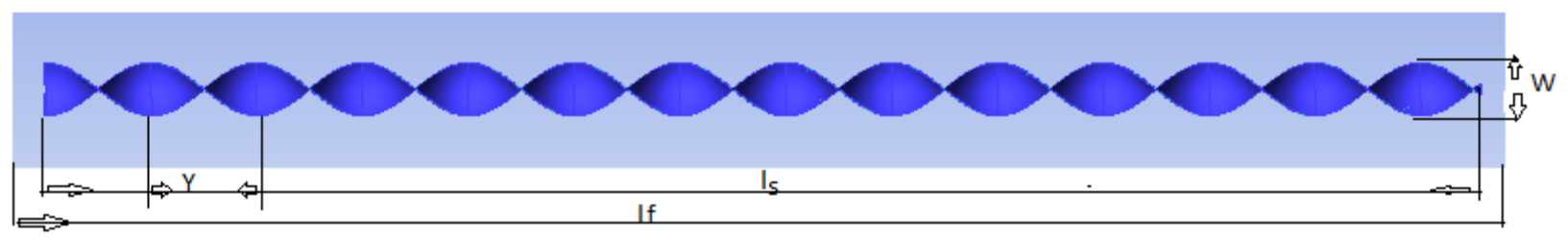

Fig. 1. The geometry of flow domain PTT

$\mathrm{Y} / \mathrm{W}=3.0, \mathrm{LR}=1, \mathrm{D}=19 \mathrm{~mm}, \mathrm{~W}=18 \mathrm{~mm}, \mathrm{y}=54 \mathrm{~mm}$.

The geometry of DTT is shown in Figure 2 with a Diameter of Dimple is $10 \mathrm{~mm}$ and the Pitch of the dimple is $y$.

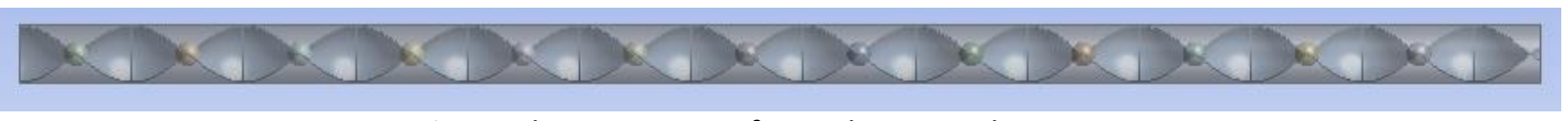

Fig. 2. The geometry of Dimple Twisted Tape DTT

\subsection{Governing Equations and Boundary Conditions}

Continuity equation

D. $V=0$ 
Momentum equation

$\frac{\partial(\rho V)}{\partial t}+\nabla \cdot(\rho V V)=-\nabla p+\nabla \cdot \mu(\nabla V)$

Energy equation

$$
\rho C p\left(\frac{\partial T}{\partial t}+\nabla \cdot V T\right)=\nabla \cdot(k . \nabla T)
$$

Turbulence kinetic energy and equation for Renormalization group $\mathrm{k}-\varepsilon$ model is given in Eq. (4)

$\left.\frac{\partial}{\partial t}(\rho \kappa)+\frac{\partial}{\partial x_{i}}\left(\rho \kappa u_{i}\right)=\frac{\partial}{\partial x_{j}}\left[a_{k} \mu_{e f f} \frac{\partial k}{\partial x_{j}}\right)\right]+G_{k}+G_{B}-\rho \varepsilon$

For dissipation $\varepsilon$

$\left.\frac{\partial}{\partial t}(\rho \varepsilon)+\frac{\partial}{\partial x_{i}}\left(\rho \varepsilon u_{i}\right)=\frac{\partial}{\partial x_{j}}\left[a_{\varepsilon} \mu_{e f f} \frac{\partial \varepsilon}{\partial x_{j}}\right)\right]+C_{1 \varepsilon_{\kappa}}\left(G_{k}+C_{3 \varepsilon} G_{B}\right)-C_{2 \varepsilon} \rho \frac{\varepsilon^{2}}{\kappa}$

Each region of the domain has been specified with boundary conditions. The internal region has been specified as the fluid domain.

The boundary condition for wall

$\mathrm{U}, \mathrm{V}=0,0$ and $\mathrm{q}=\mathrm{W}_{\text {all }}$

At the inlet of the pipe is

$U=U_{\text {in }}, V=0, T=T_{\text {in }}$

A fully developed flow has been specified at the outlet with $P=0$.

$\mathrm{Nu}=\mathrm{hD} / \mathrm{k}$

The non-dimension number

$\operatorname{Re}=\rho U D / \mu$

\subsection{Grid Resolution}

To obtain high accuracy of numerical results grid independence test was conducted, four different grids were used for each domain as shown in Table 1. The temperature at the exit of the domain has been chosen as the variable for the grid independence test for Reynolds number 20000. Results of temperature for grid resolution test of the plain tube as shown in Table 1 for PT, there is a variation of $2.12 \%, 3.0 \%$, and $3.1 \%$ in comparing the values of temperature obtained in the grids with the total number of cells 476372,524705 and 553621 respectively with the grid with the number of cells 438509. Cells 596230 give the variable output of temperature at outlet less than cells 553621 . Hence cells 553621 have been optimized for analysis. For PTT Figure 3 indicates a variation of 2.8\%, 3.4\%, 
and $4.0 \%$ in comparing the values of temperature in the grids the number of cells 563472,1036053 , and 1223856 respectively with the grid with the number of cells 523085 . The cells 1282560 give the variable output of temperature less than cells 1223856 . Hence cells 1223856 have been optimized for analysis.

Table 1

Grid resolution study

\begin{tabular}{llllll}
\hline Domain & \multicolumn{5}{l}{ Number of cells } \\
\hline PT & 438509 & 476372 & 524705 & 553621 & 596230 \\
PTT & 523085 & 563472 & 1036053 & 1223856 & 1282560 \\
\hline
\end{tabular}

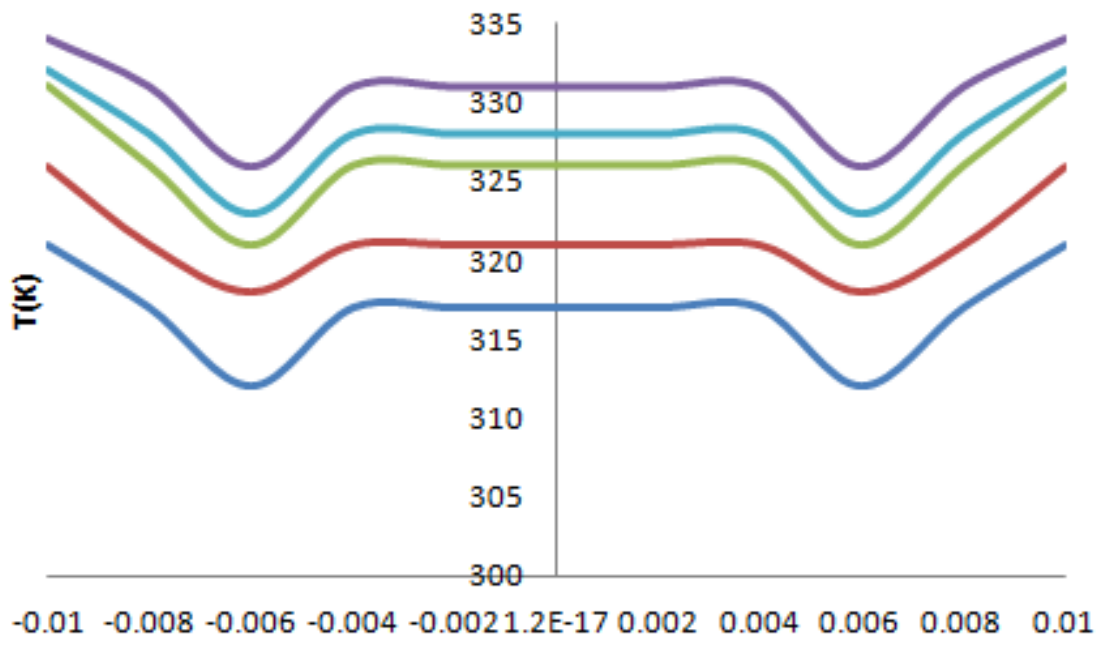

$r(m)$

Fig. 3. Results of temperature for grid resolution of PTT tube

\section{Computational Results and Discussions}

Results of Nu obtained for RNG $k-\varepsilon$ model and friction factor $f$, for PT, PTT, and DTT tube is compared with experimental data of Seemawute and Eiamsa-ard [1], correlation of Gnielinski (PT) and Kidd (PTT). Effect of PTT, DTT inserts on energy transfer, and friction factor is reported in the present section.

The Gnielinski correlation is given as

$\mathrm{Nu}=\frac{\left(\frac{f}{8}\right)(R e-1000) \operatorname{Pr}}{1+12.7(f / 8)^{\frac{1}{2}}\left(\operatorname{Pr}^{\frac{2}{3}}-1\right)}$

The Kidd correlation is defined as

$N u=0.024 \operatorname{Re}^{0.8} \operatorname{Pr}^{0.4}\left[\frac{y}{y-1}\right]^{1.1}\left[\frac{T_{b}}{T_{w}}\right]^{0.7}\left[1+(D / L)^{0.55}\right] \times\left[\frac{\pi+2-2 \delta / D}{\pi-\frac{4 \delta}{D}}\right]^{0.2}\left[\frac{\pi}{\pi-\frac{4 \delta}{D}}\right]^{0.8}$

The friction factor is obtained from the Petukhov correlation for the plain pipe is given in Eq. (10).

$f=(0.790 \ln \operatorname{Re}-1.64)^{-2}$ 
The results of the experiment of Seemawute and Eiamsa-ard [1] and, Gambill and Bundy correlation were used for the validation of the friction factor of the tube induced with PTT and DTT as shown in Figure 5. And The Gambill and Bundy correlation is given as Eq. (11).

$f=0.046 R e^{-0.2}\left[\frac{\pi+2-2 \delta / D}{\pi-\frac{4 \delta}{D}}\right]^{1.8}\left[\frac{\pi}{\pi-\frac{4 \delta}{D}}\right]^{1.2}+\frac{0.0525}{y^{1.31}}\left[\frac{2000}{R e}\right]^{0.81}\left[\frac{\pi+2-2 \delta / D}{\pi-\frac{4 \delta}{D}}\right]^{0.388}\left[\frac{\pi}{\pi-\frac{4 \delta}{D}}\right]^{2.62}$

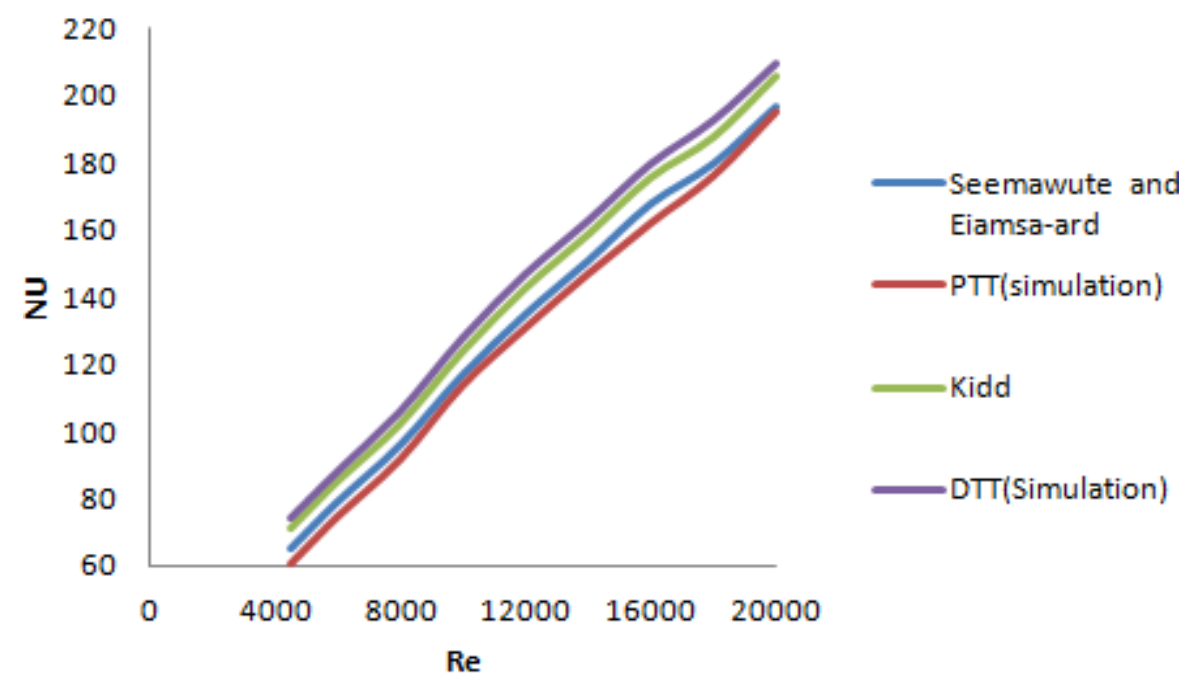

Fig. 4. Nu vs. Re, Validation of simulation work with experiment and correlation work

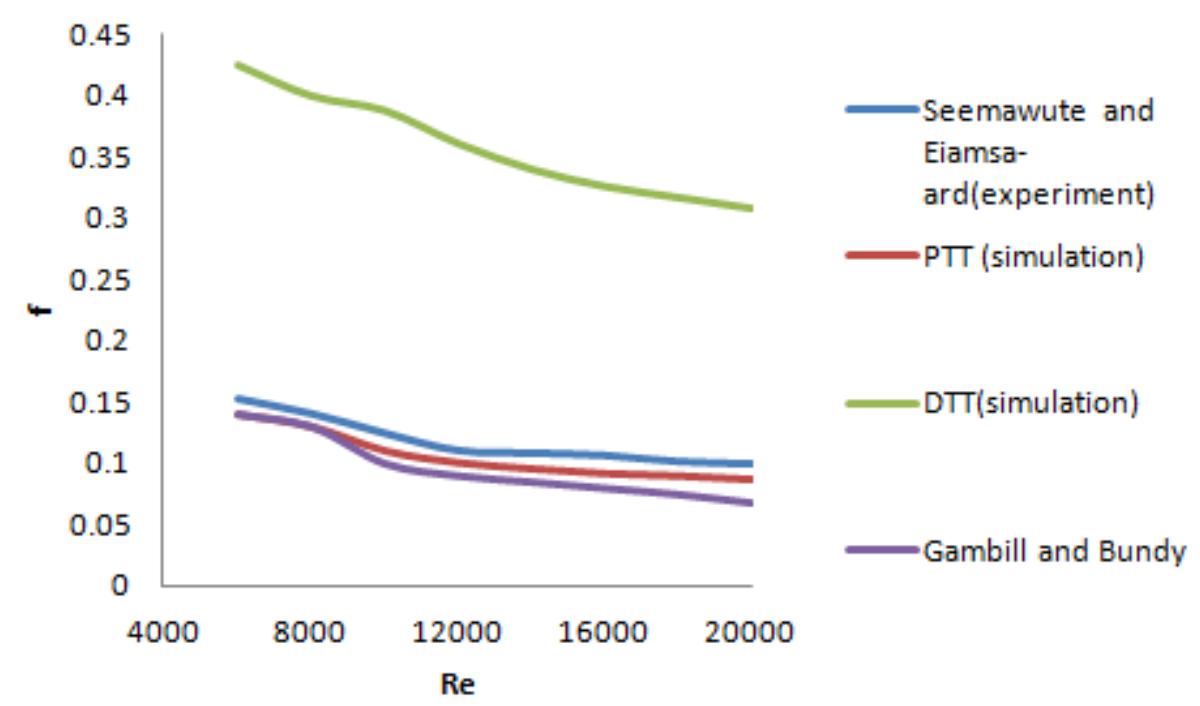

Fig. 5. Friction factor vs. Re Validation of simulation work with experiment and correlation work

\subsection{Effect of PTT and DTT}

Figure 4 and Figure 5 indicate validation of PTT, DTT simulation work with experimental work and correlation. The Nusselt number of (PT) correlates with the experimental performance of Seemawute and Eiamsa-ard [1] With a maximum deviation of 4.15 percent, but with a maximum deviation of 6.10 percent following the Gnielinski correlation. The Nusselt number has a maximum deviation of 3.89 
percent compared to the experimental data for PTT insert [1]. A maximum deviation of 7.54 percent is provided by its agreement with the Kidd correlation (PTT).

The Nusselt number for DTT inserts has a maximum variance of 3.5 percent relative to Kidd correlation (PTT), but it is in line with experimental findings Seemawute and Eiamsa-ard [1] with a 7.65 percent overall deviation.

\subsection{Effect of Friction Factor}

Simulation results of PTT fairly predict Gambill and Bundy correlation from around $\operatorname{Re}=5000$ to $\operatorname{Re}$ $=8000$. The value of friction factor is higher at low Reynolds number because momentum overcomes the viscous force of fluid as Reynolds number increases. Above $\mathrm{Re}=8000$ the simulated (PTT) match with experimental results of Seemawute and Eiamsa-ard [1] with a maximum deviation of 5.15\% but it is in agreement with the Gambill and Bundy correlation with a maximum deviation of $5.10 \%$.

The friction factor versus Re number of PTT, DTT, Seemawute, and Eiamsa-ard [1] (Experiment) and Gambill and Bundy correlation work are shown in Figure 5, with the increase of Re number friction factor tends to decrease. It is observed that any insert within a tube when compared with plain tube there is a trend of reducing friction factor with increasing Reynolds number this is due to blockage of flow and thereby reducing the momentum of flow. The dimples on the twisted tube will have high friction over the plain tube. The presence of a dimple on the tube causes fluid disturbance increasing pressure. The friction factor of DTT is 60 to $70 \%$ higher than that of PTT at different Reynolds numbers.

\subsection{Velocity Contour}

To understand flow physics Velocity of flow at selected locations is shown in Figure 6 for plain tube, twisted tape tube and dimple twisted tape tube. The location of 0.7 (frame $c$ ) in the DTT in Figure $6(C)$ increases the swirl and the magnitude of the velocity in this region higher than that in the upstream regions, the domain for plain tube maximum velocity is induced at the center of the pipe and diminishes has it move towards the wall of the pipe. Indicating flow is fully developed at this location. The velocity for a plain tube is the same at all locations we can observe from Figure 6(A). Velocity is the same at all locations for a plain tube. When the plain twisted tape and dimples on twisted tape are induced velocity will increase than that of the plain tube due to the swirl of flow generated.

(A)

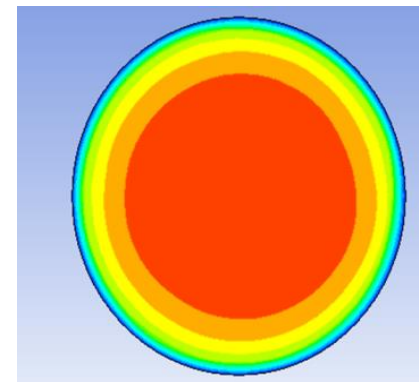

(a)

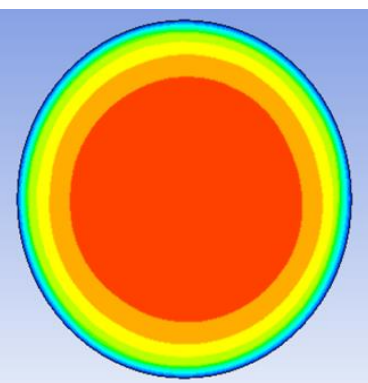

(b)

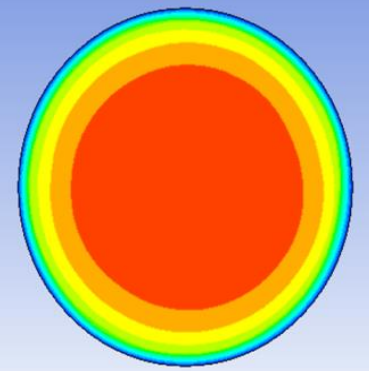

(c)

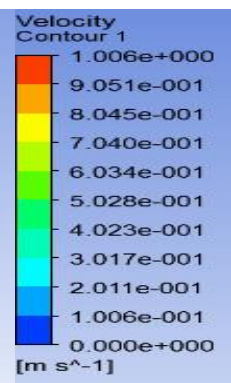

[m sn-1] 
(B)

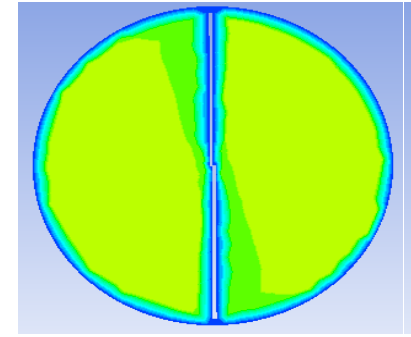

(a)

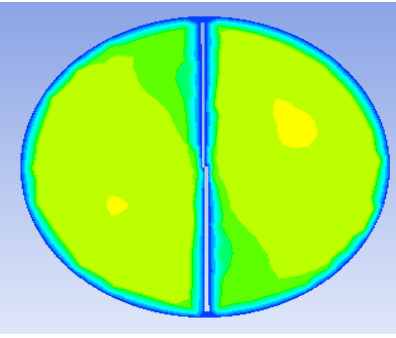

(b)

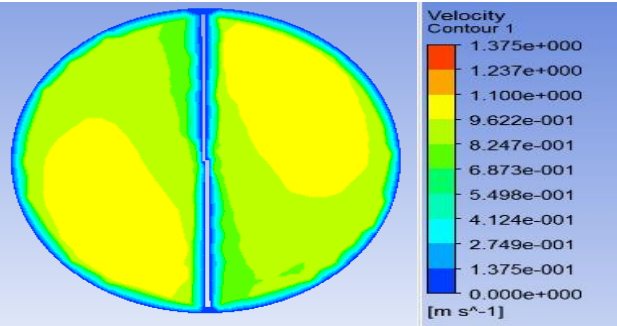

(c)

(C)

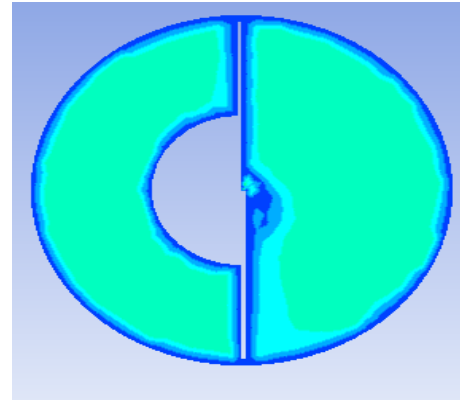

(a)

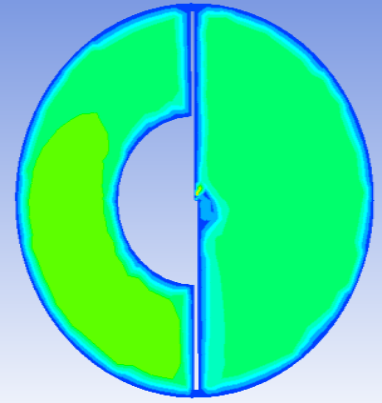

(b)

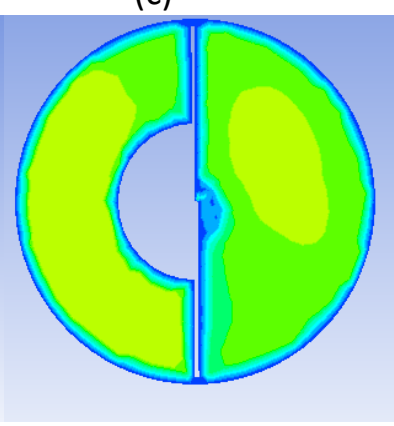

(c)

Fig. 6. Contour plot of velocity for PT(A), PTT(B) and DTT(C) tube for $\mathrm{Re}=20000$ at axial location (a) $0.5 \mathrm{~m}$, (b) $0.55 \mathrm{~m}$, (c) $0.7 \mathrm{~m}$

\subsection{Temperature Contours}

The temperature contours for plain, twisted tape, and dimple twisted tape tube at different locations for Reynolds number 20000 as shown in Figure 7. The temperature contours for a plain tube are the same at all locations. Due to inserts which causes fluid to undergo mixing thereby increasing the temperature at all locations when compared with a plain tube. Due to the absence of $\mathrm{DTT}$, there is a decrease of temperature of around $8.5 \%$ in the plain twisted tube when compared with dimple twisted tape tube. In Figure $7(B)$, the temperature contours at different locations for twisted tape tube is $6.5 \%$ higher than that of plain tube Because of an insert of strips causes flow disturbance which gives rise to augmentation of energy transfer. Due to the presence of dimples on strips, a small amount of surface area will increase and also disturbance to the flow field hence at an axial location of $0.7 \mathrm{~m}$ (Figure 7 (C) (Frame $\mathrm{c}$ ) the temperature is found to be $1.5 \%$ to $2.0 \%$ higher than upstream axial locations of $0.5 \mathrm{~m}$ (Figure $7(\mathrm{C})$ (frame a) and $0.6 \mathrm{~m}$ (Figure $7(\mathrm{C})$ (Frame b).

(A)

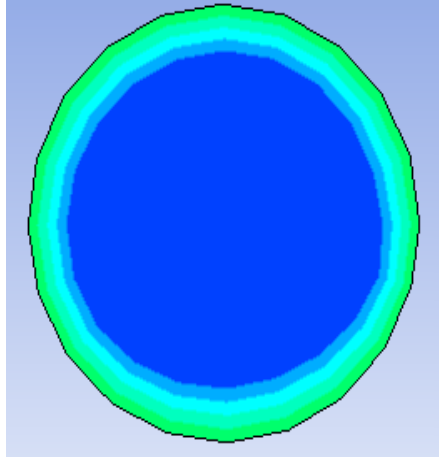

(a)

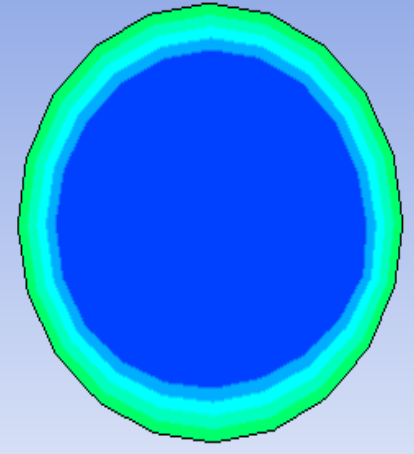

(b)

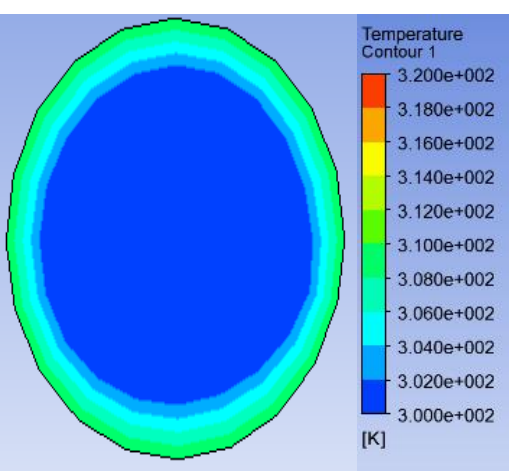

(c) 
(B)

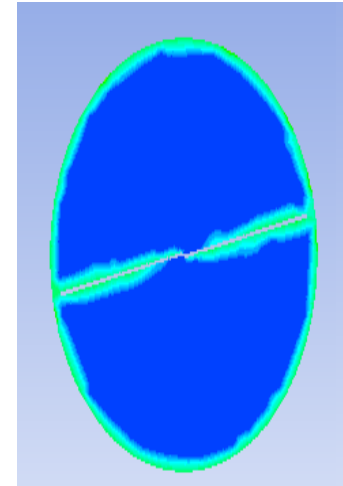

(a)

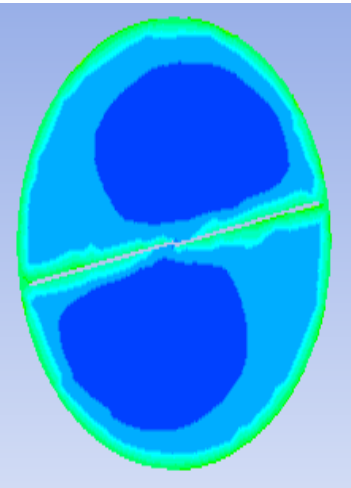

(b)

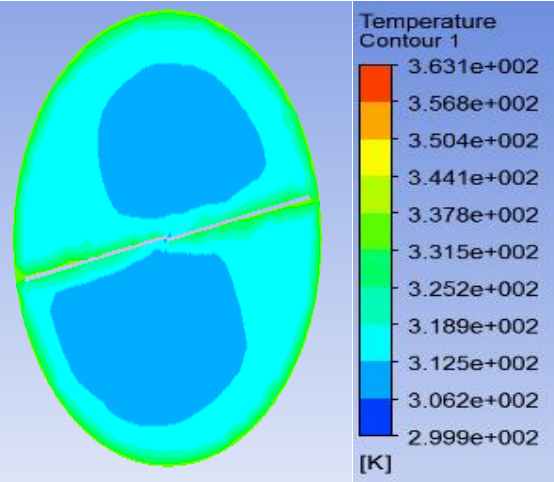

(c)

(C)

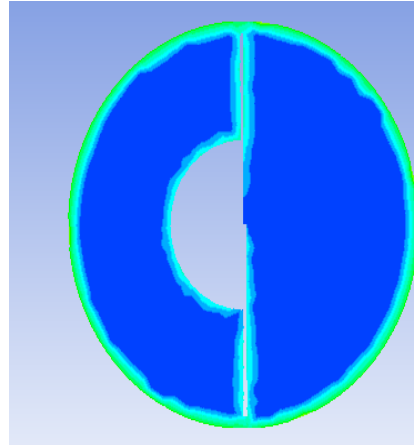

(a)

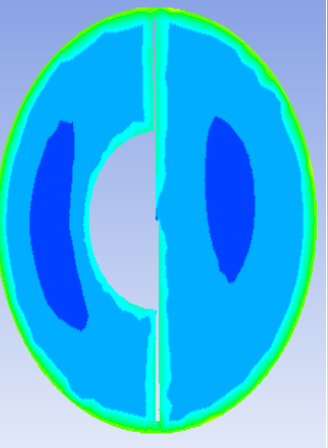

(b)

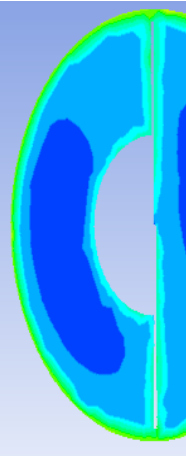

(c)

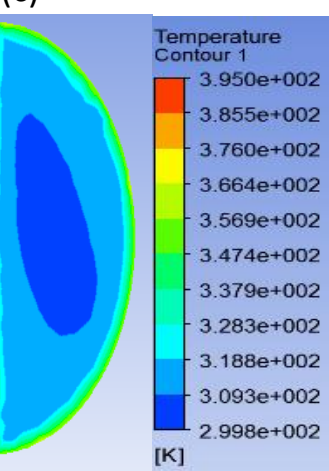

(c)

Fig. 7. Temperature contour plots $\mathrm{PT}(\mathrm{A}), \mathrm{PTT}(\mathrm{B})$ and $\mathrm{DTTT}(\mathrm{C})$ for $\mathrm{Re}=20000$ at axial location (a) $0.5 \mathrm{~m}$, (b) $0.55 \mathrm{~m}$, (c) $0.7 \mathrm{~m}$

\subsection{Effect on the Thermal Performance Factor}

The implication of inserts in the tube on the thermal performance factor is shown in Figure 8 . The increase in heat transfer rate yields the highest thermal performance which is obtained for dimple extrusion on twisted tape. However, all inserts are yielding thermal performance above unity which gives rise to the intensification of heat transfer. It is observed that the thermal performance of the induced tube that is PTT and DTT are above unity. It compares the thermal performance of plain tube and induced tube with same pumping power and is mathematically given by Eq. (12)

$\boldsymbol{\eta}=\mathrm{Nu} / \mathrm{Nu}_{\mathrm{p}}\left(\mathrm{f} / \mathrm{f}_{\mathrm{p}}\right)^{-1 / 3}$

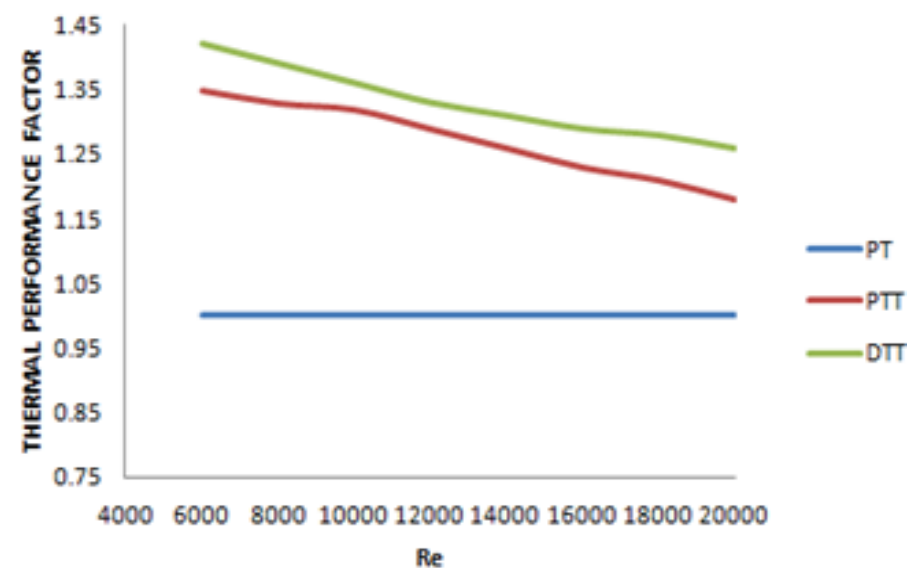

Fig. 8. Effect of PT, PTT, and DTT on thermal performance factor vs. Reynolds number 


\section{Conclusions}

The following conclusion can be drawn from the present analysis.

I. The DTT tube presents better heat transfer intensification than PTT and PT.

II. The rate of heat transfer is always higher for full-length TT pipe with dimples than that of PTT.

III. The simulation results of Nusselt number versus Re number of the PT, PTT, and DTT with the experimental data gives a variation of $4.15 \%, 3.89 \%$, and $7.65 \%$.

IV. Thermal performance factor for PTT and DTT is greater than unity leads to enhancement of heat transfer.

\section{Acknowledgment}

"This research was not funded by any grant".

\section{References}

[1] Seemawute, Panida, and Smith Eiamsa-Ard. "Thermohydraulics of turbulent flow through a round tube by a peripherally-cut twisted tape with an alternate axis." International Communications in Heat and Mass Transfer 37, no. 6 (2010): 652-659. https://doi.org/10.1016/j.icheatmasstransfer.2010.03.005

[2] Liao, Q., and M. D. Xin. "Augmentation of convective heat transfer inside tubes with three-dimensional internal extended surfaces and twisted-tape inserts." Chemical Engineering Journal 78, no. 2-3 (2000): 95-105. https://doi.org/10.1016/S1385-8947(00)00134-0

[3] Yadav, R. J., and Atuul S. Padalkar. "CFD analysis for heat transfer enhancement inside a circular tube with halflength upstream and half-length downstream twisted tape." Journal of Thermodynamics 2012 (2012). https://doi.org/10.1155/2012/580593

[4] Chiu, Yu-Wei, and Jiin-Yuh Jang. "3D numerical and experimental analysis for thermal-hydraulic characteristics of air flow inside a circular tube with different tube inserts." Applied Thermal Engineering 29, no. 2-3 (2009): $250-258$. https://doi.org/10.1016/i.applthermaleng.2008.02.030

[5] Abed, Azher M., Hasan Sh Majdi, Zainab Hussein, Doaa Fadhil, and Ammar Abdulkadhim. "Numerical analysis of flow and heat transfer enhancement in a horizontal pipe with P-TT and V-Cut twisted tape." Case Studies in Thermal Engineering 12 (2018): 749-758. https://doi.org/10.1016/j.csite.2018.10.004

[6] Eiamsa-Ard, Smith, K. Wongcharee, and S. Sripattanapipat. "3-D Numerical simulation of swirling flow and convective heat transfer in a circular tube induced by means of loose-fit twisted tapes." International Communications in Heat and Mass Transfer 36, no. 9 (2009): $947-955$. https://doi.org/10.1016/j.icheatmasstransfer.2009.06.014

[7] Promvonge, Pongjet, and Smith Eiamsa-Ard. "Heat transfer behaviors in a tube with combined conical-ring and twisted-tape insert." International Communications in Heat and Mass Transfer 34, no. 7 (2007): 849-859. https://doi.org/10.1016/j.icheatmasstransfer.2007.03.019

[8] Chang, Shyy Woei, Tsun Lirng Yang, and Jin Shuen Liou. "Heat transfer and pressure drop in tube with broken twisted tape insert." Experimental Thermal and Fluid Science 32, no. 2 (2007): 489-501. https://doi.org/10.1016/i.expthermflusci.2007.06.002

[9] Kumar, A., and B. N. Prasad. "Investigation of twisted tape inserted solar water heaters-heat transfer, friction factor and thermal performance results." Renewable Energy 19, no. 3 (2000): 379-398. https://doi.org/10.1016/S09601481(99)00061-0

[10] Song, Si-hong, Qiang Liao, and Wei-dong Shen. "Laminar heat transfer and friction characteristics of microencapsulated phase change material slurry in a circular tube with twisted tape inserts." Applied Thermal Engineering 50, no. 1 (2013): 791-798. https://doi.org/10.1016/j.applthermaleng.2012.07.026

[11] Salman, Sami D., Abdul Amir H. Kadhum, Mohd S. Takriff, and Abu Bakar Mohamad. "CFD analysis of heat transfer and friction factor characteristics in a circular tube fitted with quadrant-cut twisted tape inserts." Mathematical Problems in Engineering 2013 (2013). https://doi.org/10.1155/2013/273764

[12] Eiamsa-ard, Smith, K. Wongcharee, P. Eiamsa-Ard, and C. Thianpong. "Heat transfer enhancement in a tube using delta-winglet twisted tape inserts." Applied Thermal Engineering 30, no. 4 (2010): 310-318. https://doi.org/10.1016/j.applthermaleng.2009.09.006 
[13] Sarviya, R. M., and Veeresh Fuskele. "Heat transfer and pressure drop in a circular tube fitted with twisted tape insert having continuous cut edges." Journal of Energy Storage 19 (2018): 10-14. https://doi.org/10.1016/i.est.2018.07.001

[14] Ibrahim, E. Z. "Augmentation of laminar flow and heat transfer in flat tubes by means of helical screw-tape inserts." Energy Conversion and Management 52, no. 1 (2011): 250-257. https://doi.org/10.1016/i.enconman.2010.06.065

[15] Eiamsa-Ard, Smith, and Pongjet Promvonge. "Performance assessment in a heat exchanger tube with alternate clockwise and counter-clockwise twisted-tape inserts." International Journal of Heat and Mass Transfer 53, no. 78 (2010): 1364-1372. https://doi.org/10.1016/j.ijheatmasstransfer.2009.12.023

[16] Eiamsa-Ard, S., K. Wongcharee, P. Eiamsa-Ard, and C. Thianpong. "Thermohydraulic investigation of turbulent flow through a round tube equipped with twisted tapes consisting of centre wings and alternate-axes." Experimental Thermal and Fluid Science 34, no. 8 (2010): 1151-1161. https://doi.org/10.1016/i.expthermflusci.2010.04.004

[17] Thianpong, C., P. Eiamsa-Ard, P. Promvonge, and S. Eiamsa-Ard. "Effect of perforated twisted-tapes with parallel wings on heat tansfer enhancement in a heat exchanger tube." Energy Procedia 14 (2012): 1117-1123. https://doi.org/10.1016/j.egypro.2011.12.1064

[18] Hasanpour, A., M. Farhadi, and K. Sedighi. "A review study on twisted tape inserts on turbulent flow heat exchangers: The overall enhancement ratio criteria." International Communications in Heat and Mass Transfer 55 (2014): 53-62. https://doi.org/10.1016/i.icheatmasstransfer.2014.04.008

[19] Maradiya, Chirag, Jeetendra Vadher, and Ramesh Agarwal. "The heat transfer enhancement techniques and their thermal performance factor." Beni-Suef University Journal of Basic and Applied Sciences 7, no. 1 (2018): 1-21. https://doi.org/10.1016/i.bjbas.2017.10.001

[20] Vashistha, Chaitanya, Anil Kumar Patil, and Manoj Kumar. "Experimental investigation of heat transfer and pressure drop in a circular tube with multiple inserts." Applied Thermal Engineering 96 (2016): 117-129. https://doi.org/10.1016/i.applthermaleng.2015.11.077

[21] García, A., J. P. Solano, P. G. Vicente, and A. Viedma. "The influence of artificial roughness shape on heat transfer enhancement: Corrugated tubes, dimpled tubes and wire coils." Applied Thermal Engineering 35 (2012): $196-201$. https://doi.org/10.1016/i.applthermaleng.2011.10.030

[22] Yuan, Wei, Guoyun Fang, Xiaoqing Zhang, Yong Tang, Zhenping Wan, and Shiwei Zhang. "Heat transfer and friction characteristics of turbulent flow through a circular tube with ball turbulators." Applied Sciences 8, no. 5 (2018): 776. https://doi.org/10.3390/app8050776

[23] Wijayanta, Agung Tri, Pranowo,, Mirmanto, Budi Kristiawan, and Muhammad Aziz. "Internal flow in an enhanced tube having square-cut twisted tape insert." Energies 12 (2019): 306. https://doi.org/10.3390/en12020306

[24] Juera-ong, Panupong, Nioh Puzu, and Chayut Nuntadusit. "Experiment Study on Heat Transfer and Flow Structure of The Single Row Circular Orifice Jets Injecting into Turbulent Boundary Layer." Journal of Advanced Research in Fluid Mechanics and Thermal Sciences 78, no. 2 (2021): 47-55.

[25] Japar, Wan Mohd Arif Aziz, Nor Azwadi Che Sidik, Natrah Kamaruzaman, Yutaka Asako, and Nura Mu'az Muhammad. "Hydrothermal performance in the Hydrodynamic Entrance Region of Rectangular Microchannel Heat Sink." Journal of Advanced Research in Numerical Heat Transfer 1, no. 1 (2020): 22-31.

[26] Yusof, Nur Syamila, Siti Khuzaimah Soid, Mohd Rijal Illias, Ahmad Sukri Abd Aziz, and Nor Ain Azeany Mohd Nasir. "Radiative Boundary Layer Flow of Casson Fluid Over an Exponentially Permeable Slippery Riga Plate with Viscous Dissipation." Journal of Advanced Research in Applied Sciences and Engineering Technology 21, no. 1 (2020): 41-51. https://doi.org/10.37934/araset.21.1.4151

[27] Harish, H. V., K. Manjunath, and T. Rangaswamy. "Numerical Analysis of Flow and Heat Transfer Enhancement in A Horizontal Pipe with Plain and Dimple Twisted Tape." Journal of Advanced Research in Fluid Mechanics and Thermal Sciences 82, no. 2 (2021): 106-119. https://doi.org/10.37934/arfmts.82.2.106119 